\title{
Surface Modification of SiC Reinforcements \& Its Effects on Mechanical Properties of Aluminium Based MMC
}

\author{
Mohan Vanarotti ${ }^{1, a}$, Shrishail $P^{2}, B$ R. Sridhar ${ }^{3}$, K.Venkateswarlu ${ }^{4, b}$ \\ \& S A. Kori ${ }^{5, \mathrm{C}}$ \\ ${ }^{1}$ Christ University Faculty of Engg, Bangalore, 560 060, India \\ ${ }^{2}$ ITER-India (IPR) Gandhinagar Gujarat, 382 010, India \\ ${ }^{3}$ SEA College of Engg. \& Tech, Virgo Nagar, Bangalore - 560 049, India \\ ${ }^{4}$ CSIR, National Aerospace Laboratories, Bangalore -560 017, India \\ ${ }^{5}$ Basaveshawar Engg. College, Bagalkot, 587 301, India \\ amohan1.bv@gmail.com, ${ }^{\mathrm{b}}$ karodi2002@yahoo.co.in, ${ }^{\mathrm{C}}$ kori.shivu@gmail.com
}

Keywords: Metal matrix composite; SiC; Wettability; A356; Hardness; Coating.

\begin{abstract}
Aluminum (A356)-SiC metal matrix composites were fabricated by using liquid metallurgy route. To improve the interfacial bonding between the $\mathrm{Al}$ and $\mathrm{SiC}$, an attempt has been made to coat the $\mathrm{SiC}$ particles with $\mathrm{Ni}$ and $\mathrm{Cu}$. Electroless process was used for coating the reinforced particle. This surface modification due to electroless coating on $\mathrm{SiC}$ particles was confirmed with SEM/ EDS analysis. Processing parameters such as melt temperature, stirring speed, stirring time, and preheating temperature were optimized. SiC content in Al-SiC MMC were taken from 5 to $15 \%$ and effect of $\mathrm{Ni}$ and $\mathrm{Cu}$ coating was studied using hardness measurements. Influence of coated $\mathrm{SiC}$ particles in $\mathrm{Al}-\mathrm{SiC}$ showed significant improvement in hardness values. Moreover, micro structural examination clearly demonstrated that $\mathrm{Cu}$ coating on $\mathrm{SiC}$ particles resulted in good metallurgical boding as compared to $\mathrm{SiC}$ particles with $\mathrm{Ni}$ coating. As a result, the hardness values of $\mathrm{Al}-\mathrm{SiC}(\mathrm{Cu})$ exhibited better hardness values as compared to $\mathrm{Al}-\mathrm{SiC}(\mathrm{Ni})$ MMCs. As expected, high $\mathrm{SiC}$ content in types of Al-SiC MMCs showed high hardness values as compared to low $\mathrm{SiC}$ content and base alloy. The present investigation suggests that $\mathrm{Cu}$ coating on $\mathrm{SiC}$ particles are more suitable as compared to $\mathrm{Ni}$ coating on $\mathrm{SiC}$ particles to synthesis $\mathrm{Al}-\mathrm{SiC}$ MMCs.
\end{abstract}

\section{Introduction}

Metal matrix composites are the engineered materials produced by mixture of two or more unlike materials, at least one of which is basically a metal. Different manufacturing processes for producing Metal matrix composites have been developed. In the present study liquid metallurgy process is adopted. Liquid metallurgy [1,2] process is the most economical method among spray deposition [3], powder metallurgy [4], liquid metal infiltration [5] and squeeze casting [6]. Wettability is the major problem in fabricating these materials and this is due to the presence of a film oxide at the surface of the aluminium [7]. But literature suggests, this problem can be resolved by either addition of the wetting agents like magnesium, calcium, titanium or zirconia [8], or by surface modification of the reinforcement particles [7]. An extensive research work has been carried on improving wettability. Particles try to float on the surface of the melt, though larger specific density of the $\mathrm{SiC}$ particles than the A356 alloy due to high surface tension and poor wetting between the particles and the melt. Zhou et al. suggested a mechanical force by stirring process cannot solve this wetting process [9]. This may be due to gas layers formed on the surface of the particle.

Hongwei Zhang et al. carried a study improving wettability by adding $\mathrm{Mg}$ as the wetting agent. They suggested the Wettability between molten Al-Mg matrix and SiC particles is improved and the surface tension of molten $\mathrm{Al}-\mathrm{Mg}$ alloy with $\mathrm{SiC}$ particle is reduced, and results in homogeneous particles distribution and high interfacial bond strength $[10,11]$. 
Ramesh et al. claims $\mathrm{Ni}$ coated $\mathrm{SiC}$ reinforced composites exhibits not only good interfacial bond between matrix and reinforcement but also improved mechanical properties compared to uncoated [11]. Many researchers used addition of wetting agents and few used surface modification by electroless deposition of metal elements for improving the wettability of the reinforcement [13]. In the present study an attempt is made to modify the surface of the reinforment by coating them with Nickel and copper separately which increases the overall surface energy of the solid, and studied their effects on mechanical properties.

\section{Surface Modification}

\section{By Nickel coating}

The steps involved in surface modification are as follows.

i. $\quad$ Cleaning the $\mathrm{SiC}$ particles with acetone for $15 \mathrm{~min}$, then washing with water

ii. Sensitization in an aqueous solution containing $\mathrm{SnCl}_{2}$ and concentrated $\mathrm{HCl}$ for 15 min, then washing with water,

iii. Activation in an aqueous solution of $\mathrm{PdCl}_{2}$ and concentrated $\mathrm{HCl}$ for $15 \mathrm{~min}$.

iv. The dried powders were gently dispersed in an electro less bath containing nickel chloride, sodium hypophosphite, sodium citrate and ammonium chloride dissolved in distilled water at $\mathrm{pH}$ 9. Nickel deposition was carried out at $800 \mathrm{C}$.

\section{By Copper}

i. Sensitized and activated dried powders as mentioned in above step were gently dispersed in an electro less bath containing Cupric sulfate, formaldehyde, sodium-potassium tartrate (Rochelle's salt), EDTA and Sodium hydroxide pellets

\section{Material Preparations}

Composites were prepared by stir casting process. A356 is taken as starting material. The chemical composition of A356 alloy is given in Table 1. Nickel and Copper coated SiC particles were selected as the reinforcing material. A356 is melted in a resistance PLC furnace in a graphite crucible. Temperature of the furnace was raised above the liquidus to melt the cut pieces of A356 alloy. Then cooled down just below the liquidus temperature, to keep the melt in a semi-solid state. The $\mathrm{Ni}$ and $\mathrm{Cu}$ coated and $\mathrm{SiC}$ particles were preheated $\sim 800{ }^{\circ} \mathrm{C}$ for $2 \mathrm{~h}$ and these preheated particles were added at this stage separately and mixed manually for about 3 minutes. At this state the viscosity of the melt is high and high degree of shearing is produced which also improves wetting of the particle. After manual mixing, the composite slurry was re-heated above its melting point followed by mechanical mixing $\sim 7$ minutes at an average stirring speed of $350 \mathrm{rpm}$. In the final mixing processes, the furnace temperature was controlled to be within $710 \pm 10^{\circ} \mathrm{C}$.A preheated $\sim 350{ }^{\circ} \mathrm{C}$ permanent graphite mould with diameters in the range of $10 \mathrm{~mm}$ to $25 \mathrm{~mm}$ was used to prepare cast bars. Finally the super heated melt was poured into the graphite mould. The preheating temperature for graphite moulds was maintained for slower cooling.

Table1. Chemical Composition of A356

\begin{tabular}{llllllll}
\hline Element & $\mathrm{Cu}$ & $\mathrm{Mg}$ & $\mathrm{Mn}$ & $\mathrm{Si}$ & $\mathrm{Fe}$ & $\mathrm{Zn}$ & $\mathrm{Al}$ \\
\hline $\mathrm{Wt} \%$ & 0.20 & 0.35 & 0.10 & 7.0 & 0.20 & 0.10 & rest \\
\hline
\end{tabular}

\section{Characterization of A356-SiC Composites}

The samples were sectioned with abrasive cutting machine without causing any damage to the surface from the as cast bars and were prepared. A $0.5 \%$ HF solution was used to etch the samples. The particle distribution and presence of $\mathrm{SiC}$ in the cast composites were identified by micrographs, SEM and EDS analysis. The microstructure of the composites was examined using a Trinocular inverted metallurgical microscope DMI-victory. SEM analysis was carried using CARLZEISS, 
EVO-18. Mechanical properties were evaluated by hardness measurement and tensile tests. The Vickers micro hardness of the as cast composites were measured by Vickers hardness tester ESSWAY, UK, with a load of $300 \mathrm{~g}$ and dwell time $10 \mathrm{~s}$.

\section{Results and Discussion}

\section{Microstructure}

Figures 1 (a-d) reveals the microstructure of the composites containing 5\% and $10 \% \mathrm{SiC}$ content coated with $\mathrm{Ni}$ and $\mathrm{Cu}$. Microstructure reveals a reasonably homogeneous distribution of $\mathrm{SiC}$ particles in the cast composite in which particles are coated with both $\mathrm{Cu}$. But the composite containing the $\mathrm{SiC}$ particles coated with $\mathrm{Ni}$ are segregated in the grain boundaries which might be the reason for poor mechanical properties compared to the composite containing $\mathrm{Cu}$ coated particles. It was found that the particles showed a strong tendency to accumulate in the colonies which froze in the last stage of solidification as shown in fig $\mathrm{c}$ and $\mathrm{d}$.
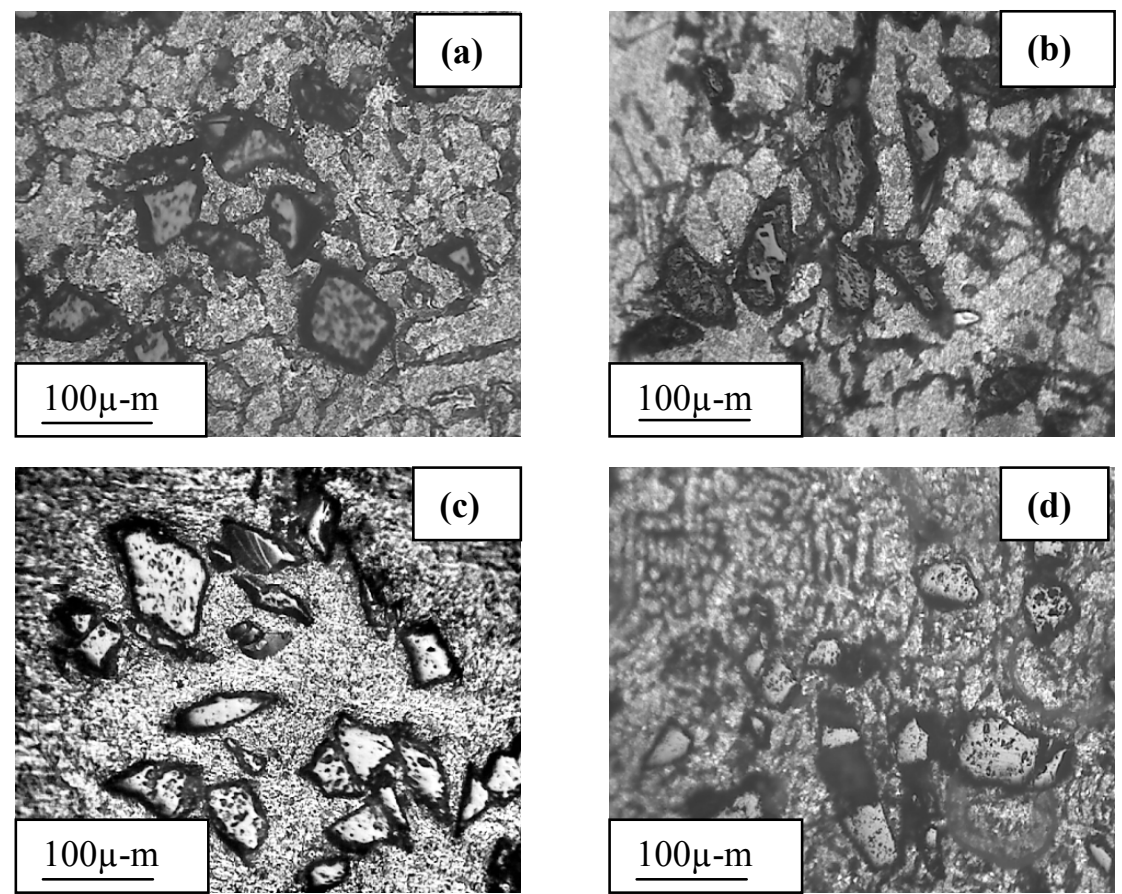
Fig1.a) A356-5SiC (Ni)
b) $\mathrm{A} 356-5 \mathrm{SiC}(\mathrm{Cu})$
c) $\mathrm{A} 356-10 \mathrm{SiC}(\mathrm{Cu})$
d) A356-10SiC (Ni)

\section{SEM and EDS Analysis}

Fig. 2 and 3 shows the SEM and EDS analysis of $\mathrm{Ni}$ and $\mathrm{Cu}$ coated $\mathrm{SiC}$ reinforcements in A356$\mathrm{SiC}(\mathrm{Ni}) \mathrm{MMC}$ 's. In fig. 2 it is observed that $\mathrm{Ni}$ is coated on $\mathrm{SiC}$ particles. And some clusters of $\mathrm{SiC}$ particles are observed in SEM micrographs. But when it comes to particle arrangements in both $\mathrm{Ni}$ and $\mathrm{Cu}$ coated $\mathrm{SiC}$ powder there were no visible differences. But $\mathrm{Cu}$ coated particles show closer contact to A356 particles than Ni coated.

Fig. 3 shows SEM image and EDS pattern A356-SiC $(\mathrm{Cu})$ composite. It shows the qualitative analysis, indicating the presence of $\mathrm{Cu}, \mathrm{Sn}, \mathrm{Si}$ and $\mathrm{C}$. Sn was used as catalyst in coating process $\left(\mathrm{Sncl}_{2}\right)$. On the other hand, a high amount of $\mathrm{Cu}$ can be seen due to the surface modification of SiC. 

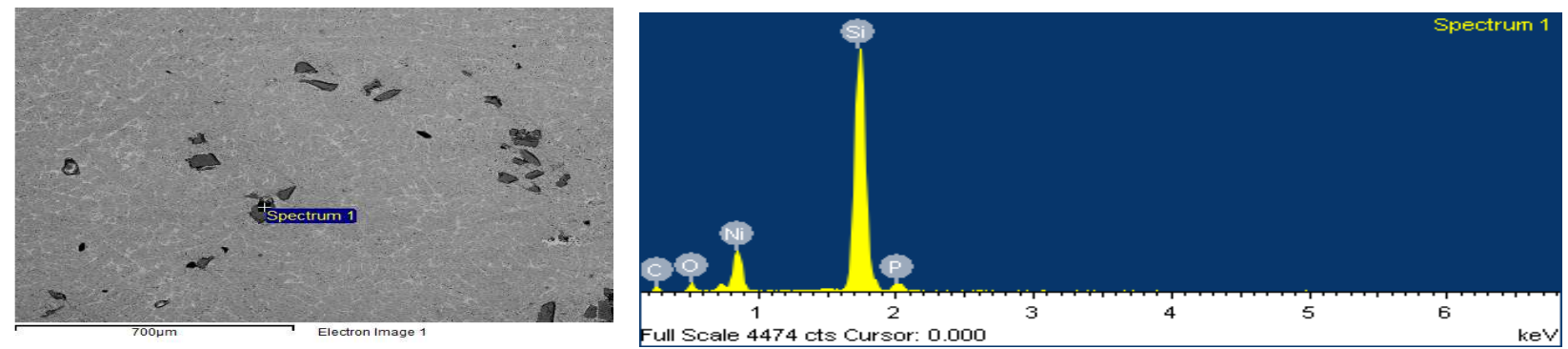

Fig.2.SEM and EDS analysis of the Ni coated SiC reinforcements in A356 composites.
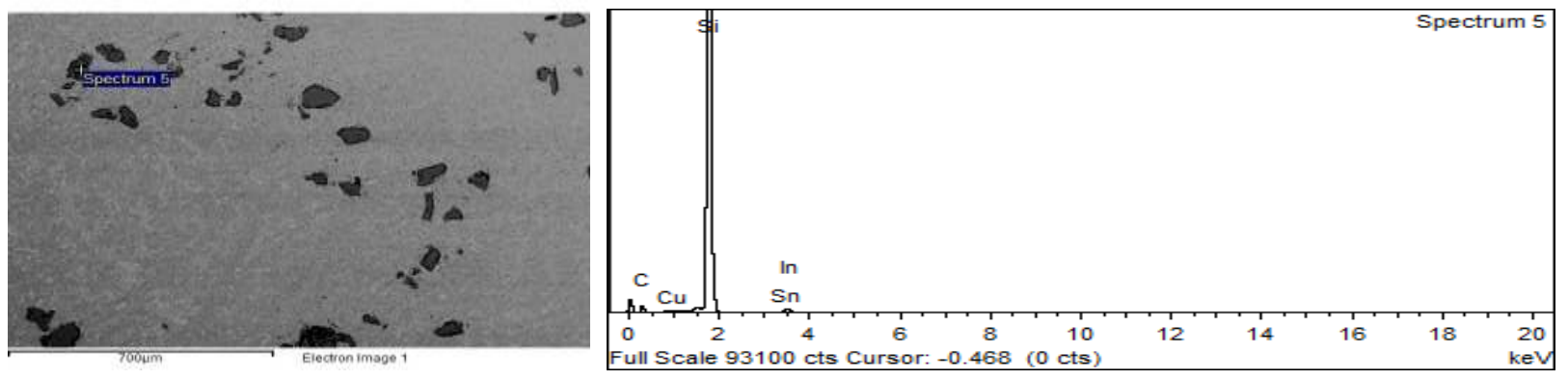

Fig.3. SEM and EDS analysis of the $\mathrm{Cu}$ coated $\mathrm{SiC}$ reinforcements in A356 composites.

\section{Mechanical Properties}

The averages hardness values of Al-SiC composites are presented in Table 2.

Table 2. Mechanical properties of Al 356-SiC MMC

\begin{tabular}{|c|c|c|}
\hline S1.No & Composition & Hardness (VHN) \\
\hline 01 & A356 & 65 \\
\hline 02 & A356-5SiC(Cu) & 78 \\
\hline 03 & A356-10SiC(Cu) & 87 \\
\hline 04 & A356-15SiC(Cu) & 95 \\
\hline 05 & A356-5SiC(Ni)* & 75 \\
\hline 06 & A356-10SiC(Ni) & 82 \\
\hline 07 & A356-15SiC(Ni) & 90 \\
\hline
\end{tabular}

From the Table. 2 it is clear that hardness is found to increase with increasing silicon carbide content in the both $\mathrm{A} 356-\mathrm{SiC}(\mathrm{Ni})$ and $\mathrm{A} 356-\mathrm{SiC}(\mathrm{Cu})$ composites. When compared, the composite containing $\mathrm{Cu}$ coated particles shows a higher hardness in all the compositions. Hardness difference of $4-6 \%$ is observed in both the composites for all compositions. It may be due to better interfacial bonding and the homogeneous distribution of the $\mathrm{SiC}$ particles. Literature also suggested coating $\mathrm{Cu}$ on ceramics is more effective than $\mathrm{Ni}$. This is due to the interfacial reaction between coating and the matrix [6].

When compared A356-SiC(Ni) with base A356 alloy, an increase of $15 \%$ in Hardness in composite containing 5\% SiC. While the composite with $10 \% \mathrm{SiC}$ shows an increase of $26 \%$ in hardness and $\sim 38 \%$ increase in the composite containing $15 \% \mathrm{SiC}$. Similar observations were made by Manoj Singla [2], Mares [13]. This increase in hardness is expected since SiC particles being very hard dispersoids, contribute positively to the hardness of the composite. The increase in hardiness is also attributed to the hard $\mathrm{SiC}$ particles which act as barriers to the movement of dislocations within the matrix.

\section{Conclusions}

A356 alloy reveals reasonable increase in hardness value with increasing silicon carbide content in both $\mathrm{Ni}$ coated $\mathrm{SiC}$ and $\mathrm{Cu}$ coated $\mathrm{SiC} \mathrm{MMC}$. This can be credited with raise in volume fraction of silicon carbide in the A356 alloy with increasing silicon carbide content. $\mathrm{Cu}$ coating on SiC 
particles resulted in good metallurgical boding compared to $\mathrm{SiC}$ particles with $\mathrm{Ni}$ coating. Hardness values of $\mathrm{Al}-\mathrm{SiC}(\mathrm{Cu})$ exhibit better hardness values as compared to $\mathrm{Al}-\mathrm{SiC}(\mathrm{Ni}) \mathrm{MMCs}$.Higher $\mathrm{SiC}$ content in both types of Al-SiC MMCs showed high hardness values as compared to low $\mathrm{SiC}$ content and base alloy. $\mathrm{Cu}$ coating on $\mathrm{SiC}$ particles is more suitable as compared to Ni coating on $\mathrm{SiC}$ particles to synthesis Al-SiC MMCs.

\section{Acknowledgement}

The authors gratefully acknowledge the financial support from the Board of research in Fusion Science and Technology, Gandhinagar, Gujarat. Under grant No. NFP-MAT-F11-01.

\section{References}

[1] B. Agarwal and D. Dixit, Fabrication of aluminium based composites by foundry techniques", Transition of Japan Institute of Metals Vol 22, No8, 1981.

[2] Manoj singla, D.Deepak Dwivedi, Lakhvir singh, Vikas chawla, Development of Aluminium Based Silicon Carbide Particulate Metal Matrix Composite, Journal of Minerals \& Materials Characterization \& Engineering, Vol. 8, No.6, ,pp 455-467,2009

[3] J. Senthilkumar, M. Balasubramanian, V. Balasubramanian, Effect of Metallurgical Factors on Corrosion Behavior of Al-SiCp Composites Fabricated by Powder Metallurgy, J Reinf Plast Comp, 28, 1087-1098, 2009

[4] Altinkok, N, Demir, A, Ozsert, I, Processing of A12O3/SiC ceramic cake preforms and their liquid Al metal infiltration, Composites, A 34, 577-582, 2003.

[5] J.F.Leng,G.H.Wu, Q.B. Zhou, Z.Y. Dou, X.L. Huang, Mechanical properties of SiC/Gr/Al composites fabricated by squeeze casting technology, Scripta Mater, 59 619-622, 2008

[6] Rajan T.P.D, Pillai, R. M., Pai, B. C, Review - Reinforcement coatings \& interfaces in aluminium MMC, Journal of Materials Science, 33,3491-3503,1998.

[7] Alonso, A., Pamies, A., Narciso, J., García-Cordovill, C., Louis E, Evaluation of the wettability of liquid aluminium ( $\mathrm{SiC}, \mathrm{TiC}, \mathrm{A} 12 \mathrm{O} 3$ ) by means of pressure infiltration, Metallurgical Transactions A, Vol 24A, 1423-1432, June 1993.

[8] W. Zhou, Z. M. Xu, Casting of SiC Reinforced Metal Matrix Composites, Journal of Materials Processing Technology, 63, 358-363,1997.

[9] Hongwei Zhang, Lin Geng, Lina Guan, Lujun Huang, Effects of Mg Content on Microstructure and Mech Properties of Sicp/Al-Mg Composites Fabricated By Semi-Solid Stirring Technique, Elsevier Materials Science and Engineering, A 528, 513-518, 2010

[10] Zhengang Liuy, Guoyin Zu, Hongjie Luo, Yihan Liu and Guangchun Yao, Influence of Mg Addition on Graphite Particle Distribution in the Al Matrix Composites, J. Mater. Science \& Technology, 26 (3), 244-250, 2010.

[11] C.S. Ramesh, R. Keshavamurthy, G.J. Naveen, Effect of extrusion ratio on wear behavior of hot extruded Al6061-SiCp (Ni-P coated) composites, Elsevier, Wear 271 1868- 1877, 2011.

[12] F. Kretza, Z. Ga, The electroless deposition of nickel on SiC particles for aluminum matrix composites, Surface and Coatings Technology $180-181,2004$.

[13] M. Mares, Some issues on tailoring possibilities for mechanical Properties of particulate reinforced metal matrix Comp, J of Optoelectronics and Adv Mat, Vol. 3, No. 1, Mar 2001 